\title{
Reduce energy consumption using efficient temperature Control inside building
}

\author{
Subbarao Yarramsetty ${ }^{\prime *}$, Divyesh Sharma ${ }^{1}$, and Siva Kumar MVN. ${ }^{1}$ \\ ${ }^{1}$ Department of Civil Engineering, NIT Warangal, Telangana State-506 004, India.
}

\begin{abstract}
One of the biggest problems we have in front of us today is climate change. However, this problem can be solved if we can take right steps individually. One of the major steps which can be taken is to reduce energy consumptions in the houses by automatic control of ACs according to users' comfort which will help in energy consumption. It is observed that a huge difference can be created by using automated temperature control system in respect to energy consumption. This paper contains study of indoor environment of the rooms in 1.8K Hostel and classrooms of Department of Civil Engineering in the Campus of NIT WARANGAL is done to analyse the comfort temperature inside the rooms for the efficient use of energy. Questionnaire survey-based study was adopted for this paper to analyse the range of thermal comfort of the students.
\end{abstract}

\section{Introduction}

In the current scenario, one of the biggest problems which is of concern on the Planet is the climate change[1]. The effect of Global Warming can be seen in different form either in the form of average increase in global atmospheric temperature or in the form of unpredictable weather. Buildings generally accounts a reasonable amount of energy consumption which means more $\mathrm{CO} 2$ emission [2]. As India a developing country, electricity consumption will keep on increasing as our population growth is high also, we are still having large energy production through non-renewable source which is resulting in energy consumption. In India building accounts for $35 \%$ of total energy consumption and is keep on increasing at $8 \%$ annually [3], which is affecting India's carbon foot print which is a matter of concern as the consumption will keep on increasing in future. If we know about how the temperature varies in that particular area or building, we can effectively utilize the consumption of energy.

Thermal comfort may be viewed as state of mind with respect to thermal satisfaction. Evaluation of thermal comfort is on the basis of codes like ISO, ASHRAE. In any accommodated space thermal adaptation can be characterize in three different processes behavioural, physiological accommodation and psychological training [4]. Indoor thermal comfort depends on proper ventilation, humidity level and performance of building envelop. Assessment of thermal comfort helps in finding quality of indoor environment and helps in optimum utilization of energy which is required for desired comfort level. A good thermal comfort has been defined as range of temperature as given by ASHRAE Standard 55, it also defines method to determine permissible temperature. Permissible Temperature ranges between $67^{\circ} \mathrm{F}$ to $87^{\circ} \mathrm{F}$ but the more accurate value depends on relative humidity. The standard specifies upper level of humidity of about $80 \%$ but has not specified any lower limit. It also specifies limit of relative humidity in occupied building to about less than $65 \%$ to reduce the condition for microbial growth[5].

For proper thermal comfort only, single parameter is not sufficient, as area having permissible temperature with high relative humidity and vice versa may provide discomfort to the occupant, it is therefore important to consider both parameter at a time and not in isolation. A proper temperature comfort especially in classroom is very important in order to minimize the artificial mode of providing comfort which will reduce the energy consumption which in turn reduce the $\mathrm{CO}_{2}$ emission.

\section{Area of Study}

Location chosen for study $1.8 \mathrm{~K}$ Ultra Mega Hostel and Postgraduate classroom of Department of Civil Engineering in the Campus of NIT Warangal. The geographical location of the campus is shown in Fig. 1. along with the front elevation of the $1.8 \mathrm{k}$ hostel. Warangal is located in the state of Telangana in Southern India. Temperature in Warangal varies between 12 to about 41 degree Celsius and average relative humidity ranges from $60 \%$ in June to about $77 \%$ in September. This study was done in the month of September 2019 which fall under ending of monsoon.

The elevation of the department of civil engineering is shown in Fig. 2(a), where the classrooms were located in the second floor. Fig. 2(b) shows the location of the study rooms in the $1.8 \mathrm{~K}$ hostel. The size of rooms in $1.8 \mathrm{~K}$ ultra mega Hostel are same but orientation of room is different depending on the wing they are located in. $1.8 \mathrm{~K}$

\footnotetext{
*orresponding author: sraoystp@student.nitw.ac.in
} 
is $\mathrm{G}+9$ floor building which consist of two wings namely Wing A and Wing B at each floor. Wing A is East facing whereas Wing B is west facing. Different room with two room in each Wings were chosen for the study. Readings of temperature were taken from 8AM to 5PM at 1-hour interval covering one floor a day in the month of September. The red dot marked in Figure2(b) represent the location of reading taken in each wing.

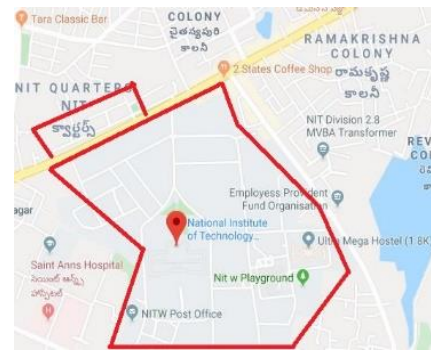

(a)

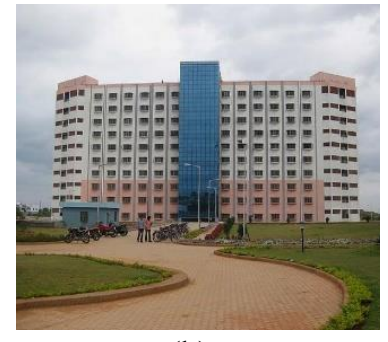

(b)
Fig. 1. (a) NIT Warangal Campus, (b) 1.8K Hostel elevation

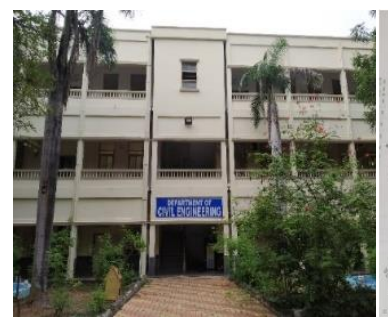

(a)

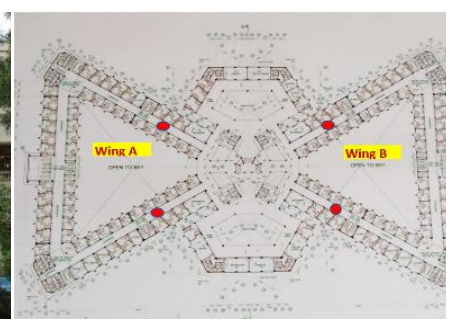

(b)
Fig. 2. (a) Civil Engineering Department, (b) Typical Floor plan of $1.8 \mathrm{~K}$ Hostel

The size of each classroom in which data is recorded are same. The vegetation covers near the classrooms are different creating somewhat different indoor lighting conditions for each classroom. The entrance view of Department of civil engineering division and the classroom arrangement is shown in Fig. 2. These classrooms are located in the 2nd floor of the Civil Engineering Department. 1.8K Ultra Mega hostel is a G+9 hostel building. The sizes of each room in the hostel are same but orientation of doors and windows and positions of the rooms vary according its location within the hostel regarding A wing (east facing) and B wing (west facing).Different rooms from different floors as well as different locations are chosen for the study so that varieties of data regarding indoor lighting comfort of students residing in these rooms can be observed.

\section{Methodology}

The temperature of air and relative humidity were measured continuously at 1-hour interval using HTC-1 Digital Temperature Humidity meter at the selected location. Study is carried to determine the indoor comfort with respect to temperature and relative humidity with the changing environment condition classrooms.Fig. 3 shows. HTC-1 Digital Temperature Humidity meter which is used for taking the reading. Readings were taken from
8AM TO 5PM at the occupied room in 1.8K Ultra Mega Hostel one floor at a time and at class room 8AM to 5PM for one week. Readings were taken at three different position namely near window, in the middle of room/class and outside the room. For the hostel room readings were taken at one floor per day with 4 rooms at each floor and two room at each wing. Average of readings at different position of room were taken to determine the average temperature of room at the particular time. Position of reading taken is marked by red mark in Figure-4 (a) and 4(b) for the class room and hostel room respectively.

Also, questionnaire survey in the selected room were done to examine the thermal comfort of the student in the room.

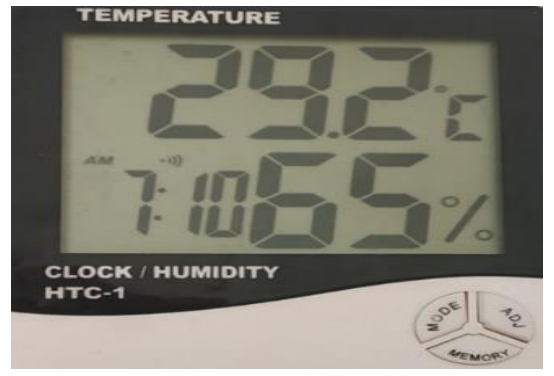

Fig. 3. HTC-1 Digital Temperature Humidity meter

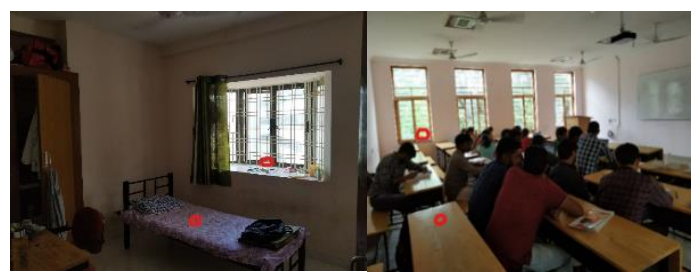

(a)

(b)

Fig.4. (a) Location of readings taken in hostel room, (b). Location of readings taken in classroom.

\section{Results}

\subsection{Analysis of Temperature and Relative Humidity in Hostel room.}

For rooms in hostel for the student to perform there self studies or other activity adequate thermal environment is a must, so that student has relax state of mind. Reading of temperature and humidity were taken from $8 \mathrm{AM}$ to $5 \mathrm{PM}$. Figure 5 shows the variation of temperature of $4^{\text {th }}$ floor at room 1 of wing A and wing B, it can be seen that at around $2 \mathrm{pm}$ temperature is maximum after which it start reducing. The red line marked in figure 5 shows the permissible temperature limit of $32^{\circ} \mathrm{C}$. During the cource of the day maximum temperature rise is about $32^{\circ} \mathrm{C}$ which has just reach the permissible limit because the period of study is in mounsoon season hence temperature rise is not very high. Conscidering the humidity graph of figure 8 , it can be seen that relative humidity is very high at begning of the day which rises to about $72 \%$. Course of the day at which temperature and humidity at its peak is point of concern since high temperature combined with high 
humidity will not allow sweat do dry easily thus creat uncomfortable condition. As there is rise in temperature humidity in air gets reduce, but during monsoon season temperature is not very high that can provide relief from high humidity.

From the table1 we can see that as we go up the floor the average temperature is lower than the bottom floor this is because the heigher floor is open to atmosphere due to which there will be better circulation of air which provide lower temperature compared to floor below. As we can see from figure 6 Relative humidity in wing $\mathrm{B}$ of the floor is lower then that of wing B it is because of the fact that B wing is towards the open side of building while wing $A$ face towards inside of building. It can also be seen from table 1 that as time proceed towards maximum temperature temperature rise is seen between $1 \mathrm{pm}$ to $2 \mathrm{pm}$ and can be related to to the figure 7 that during the same time relative humidity is generally less compared to other time, it due to the fact that heigher the temperature generally lower the temperature which is a favourable case up to a permissible limit, since either heigher relative humidity or temperature beyond permissible limit creat uncomfortable condition.

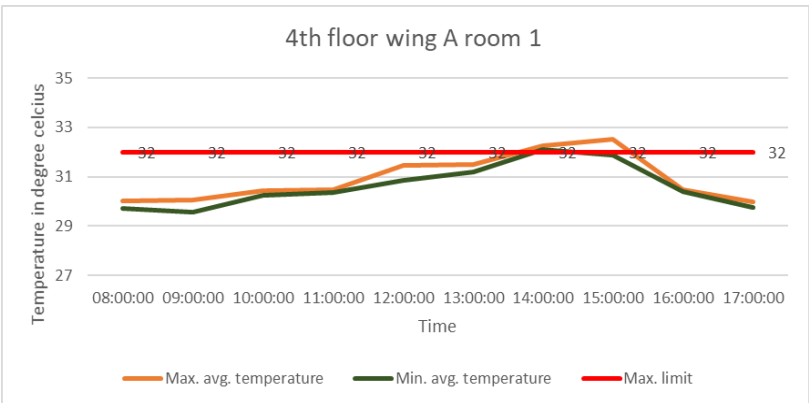

Fig 5: temperature variation of $4^{\text {th }}$ floor wing A room 1

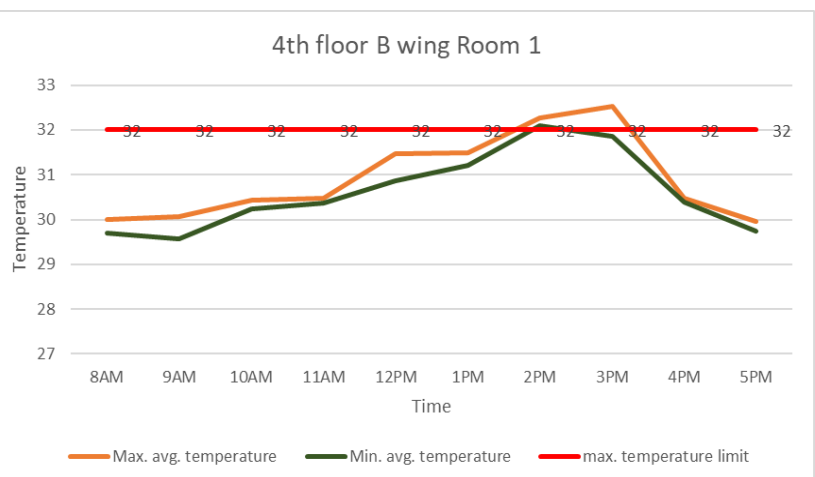

Fig. 6: temperature variation of $4^{\text {th }}$ floor wing B room 1

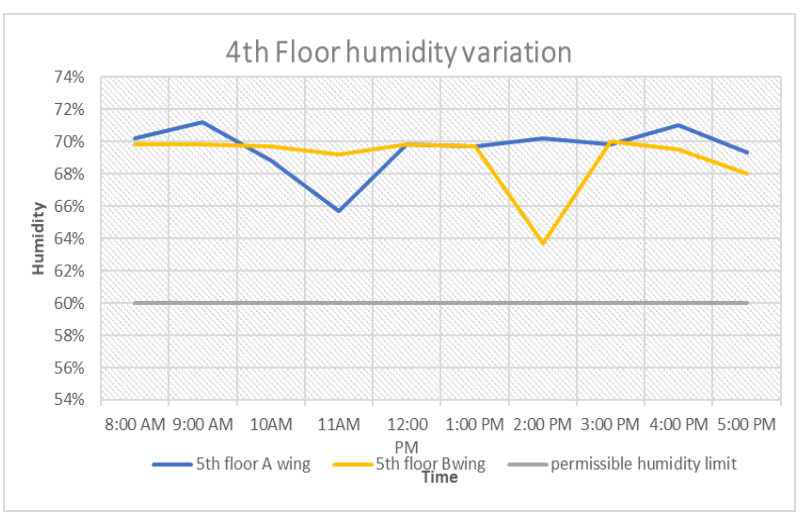

Fig 7: $4^{\text {th }}$ floor relative humidity variation

Relative humidity variation at different floor

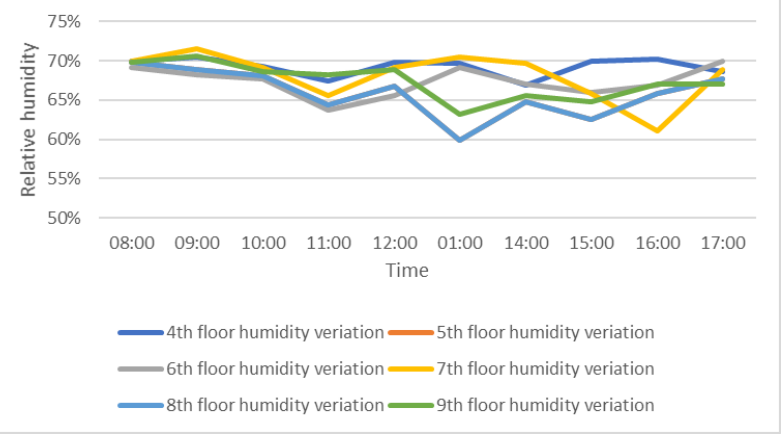

Fig.8: Graph showing humidity variation at different floor

Table1: average temperature variation of all floor at 1 hour

\begin{tabular}{|c|c|c|c|c|c|c|}
\hline $\begin{array}{c}\text { Floor } \\
\text { Time }\end{array}$ & $\begin{array}{c}\text { 4th floor } \\
\text { temperaturel } \\
\left.{ }^{\circ} \mathrm{C}\right)\end{array}$ & $\begin{array}{c}\text { 5th floor } \\
\text { temperature } \\
\left({ }^{\circ} \mathrm{C}\right)\end{array}$ & $\begin{array}{c}\text { 6th floor } \\
\text { temperature } \\
\left({ }^{\circ} \mathrm{C}\right)\end{array}$ & $\begin{array}{c}7 \text { th floor } \\
\text { temperature( } \\
\left.{ }^{\circ} \mathrm{C}\right)\end{array}$ & $\begin{array}{c}\text { 8th floor } \\
\text { temperaturel } \\
\left.{ }^{\circ} \mathrm{C}\right)\end{array}$ & $\begin{array}{c}\text { 9th floor } \\
\text { temperature } \\
\left({ }^{\circ} \mathrm{C}\right)\end{array}$ \\
\hline $08: 00$ & 29.98 & 29.22 & 29.03 & 30.01 & 29.22 & 28.67 \\
\hline $09: 00$ & 30.13 & 29.87 & 30.67 & 29.89 & 29.87 & 29.1 \\
\hline $10: 00$ & 30.38 & 30.93 & 30.68 & 30.71 & 30.93 & 29.68 \\
\hline $11: 00$ & 30.95 & 29.76 & 31.71 & 31.19 & 29.76 & 30.57 \\
\hline $12: 00$ & 31.38 & 29.98 & 31.31 & 31.35 & 29.98 & 30.68 \\
\hline $01: 00$ & 31.59 & 29.49 & 30.28 & 30.66 & 29.49 & 30.13 \\
\hline $14: 00$ & 32.34 & 29.85 & 30.49 & 30.18 & 29.85 & 30.12 \\
\hline $15: 00$ & 32.27 & 29.32 & 30.63 & 32.27 & 29.32 & 29.98 \\
\hline $16: 00$ & 31.13 & 29.41 & 30.52 & 32.78 & 29.41 & 29.84 \\
\hline $17: 00$ & 30.52 & 29.48 & 30.09 & 30.84 & 29.48 & 29.72 \\
\hline
\end{tabular}

\subsection{Analysis of Temperature and Relative Humidity in the Class rooms}

The class room functions with theoritical studies with black board, white board and projectorfor the study process, there fore it is necessary for the student to have relaxed state of mind for there performance, for this performance the be optimum adequate thermal indore environment is a must. As for the class room data is concerned, readings are taken at each class room from 
8AM to 5PM in a day for 1 week. As we can see from figure 2(a) class room at second floor has some vegetation in front of the class which results in higher humidity and lower temperature than that corresponds to hostel. Because of vegetation, the energy which is required in the form of heat which reduce the humidity level is not available hence results in higher humidity level. As, we can see from figure 10 that temperature inside the room which is far from the window is low compared to the position near the window and outside the room, it is because of proper ventilation which is provided that results in proper air flow which results in lower temperature. As we can observe from figure 10 the temperature variation for class 1 and class 3 are very similar, this due to the condition around these classrooms are similar compared to the data in class 2 which is having higher vegetation in front of the class that result in different temperature and humidity condition.

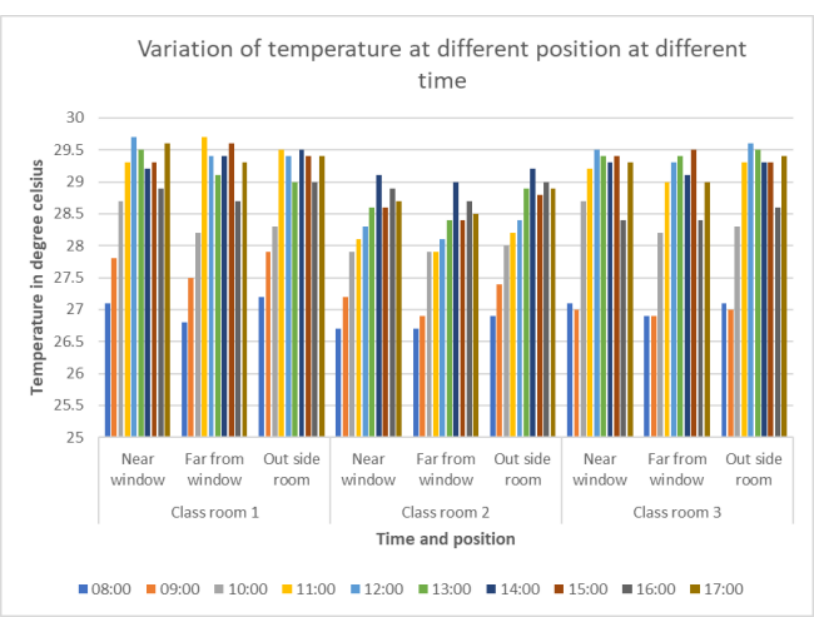

Fig.10: Temperature variation of class room at different position of class room at different time of a day.

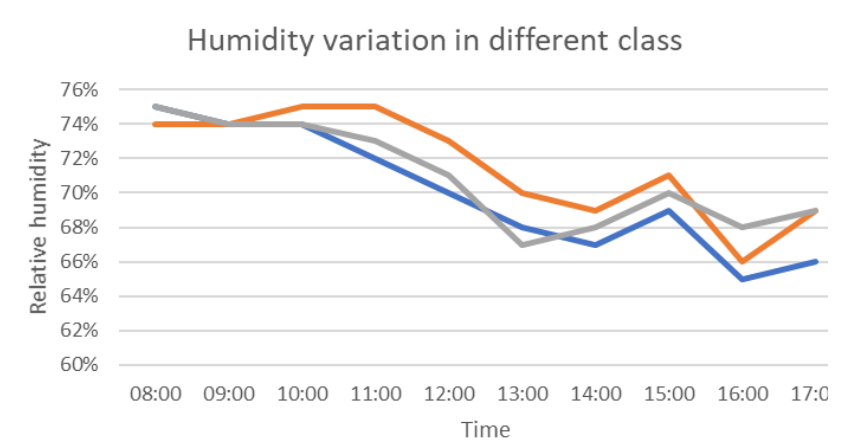

Class room 1 Humidity Class room 2 Humidity Class room 3 Humidit

Fig.9: Graphical representation of humidity in different classroom.

\section{Analysis of the questionnaire survey}

A questionnaires survey was also done by distributing question by using google form to evaluate the thermal perception of the students. Question were asked about thermal perception, humidity perception and comfort criteria with each question marked on 9-point scale with extremely uncomfortable to extremely favourable as the extreme limit. After collecting the data from student, it was found that thermal perception of the students was found to fall under comfortable criteria. About $82 \%$ of the students marked the preference as under comfortable. In order to know the reliability of response to confirm the significance of the data $\mathrm{P}$ value is found using IBM- SPSS software. For the set of three variable, the correlation variable was found to be 0.01 , which shows that the result obtained are reliable.

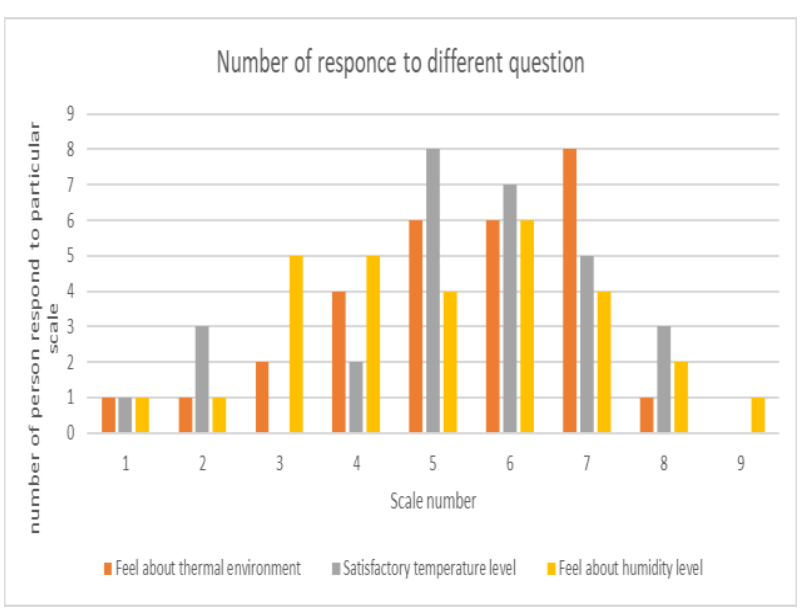

Fig.11 Number of responses for all question

\section{Discussion and Conclusion}

This study was conducted to understanding the thermal comfort of students and understanding the acceptable temperature in 1.8k Hostel and in classrooms in Campus of NIT WARANGAL. From the above study it is clear that solar radiation is main source for the room heating as the radiation can increase the temperature of rooms and can also reducing the humidity there by. It is observed that temperature of the floor above especially $9^{\text {th }}$ floor in $1.8 \mathrm{~K}$ hostel is lower compared to floor below this is because of better circulation of air since it is open to sky. From the survey it is found that even though temperature of the room is higher than the comfortable temperature response of the student was comfortable. It is mainly because of the fact that at the same time duration humidity was found relatively low which explains the response of the students in the survey. As we analyse from the study of the classroom, the vegetation cover is a must for controlling the indoor temperature of room which provide comfortable temperature required for students, which can be seen from the figure 10 that class 2 has relatively lower temperature compared to other class, which the support the role of vegetation cover in maintaining the thermal comfort of the students.(Added) With the provided good ventilation in the room almost uniform temperature and humidity can be maintained which can be depicted from the above study, good ventilation is therefore needed for providing comfortable temperature environment. By the use of proper ventilation and vegetation, energy consumption can be reduced as there will be minimum requirement of mechanical devices. 


\section{References}

1. F. Giraldo-forero, F. Cardona-escobar, and E. Castroospina, 1, 327 (2018).

2. H. Homayouni, C. S. Dossick, and G. Neff, in Constr. Res. Congr. 2014 Constr. a Glob. Netw. - Proc. 2014 Constr. Res. Congr. (2014).

3. R. Rawal, P. Vaidya, V. Ghatti, A. Ward, and T. Weidt, 313 (2002).

4. S. Rajkumar, L. R. Amirtham, and E. Horrison, 3, 2 (2009).

5. ASHRAE, Renew. Sustain. Energy Rev. 80, 1 (2011). 